\title{
Indirect immunofluorescence assay for antibody to germ tube of Candida albicans-a new diagnostic test
}

\author{
Y. M. HO ${ }^{1}$, M. H. NG ${ }^{1}$, C. H. TEOH-CHAN ${ }^{1}$, P. C. K. YUE ${ }^{2}, A_{N D}$ \\ C. T. HUANG ${ }^{1}$
}

From the Departments of Microbiology ${ }^{1}$ and Surgery ${ }^{2}$, University of Hong Kong, Hong Kong

SYNOPSIS Indirect immunofluorescent and agglutination assay were used to study the anti-Candida albicans reactivities in the serum of 13 normal subjects and 14 patients infected with $C$. albicans. A significant increase in anti-C. albicans seroreactivity was observed during infection with this organism but the increase in the anti-germ tube immunofluorescence titre was the more marked. It is evident that the anti-germ tube immunofluorescence assay is more discriminatory for C. albicans infection than the conventional agglutination assay.

Candida albicans has two growth phases. As commensal, it exists predominantly as blastospores; but, during active infection, it changes to the mycelial form (Gresham and Burns, 1960; Kozinn and Taschdjian, 1962). It has been shown that the mycelium and the blastospores are antigenically distinctive (Evans et al, 1973). Based on these two basic facts, the present study has been evolved with the development of an indirect immunofluorescence (IF) assay for the determination of antibodies to the mycelium and the application of this as a diagnostic method for Candida infection.

\section{Material and methods}

SERA

The sera from 27 subjects were studied. These consisted of 14 patients who had proven candidiasis with repeated culture, and 13 normal individuals serving as controls.

\section{CULTURE METHODS}

Blastospores were obtained by growing $C$. albicans (group A) on Sabouraud agar at $37^{\circ} \mathrm{C}$ for 48 hours. The organisms were harvested in and washed with saline. They were resuspended in saline, heated at $65^{\circ} \mathrm{C}$ for $6 \frac{1}{2}$ hours, and stored at $4^{\circ} \mathrm{C}$ until used (Hasenclever and Mitchell, 1960; 1961).

Culture medium consisting of swine serum diluted 1 in $2.5 \mathrm{v} / \mathrm{v}$ with a solution containing cystein (50

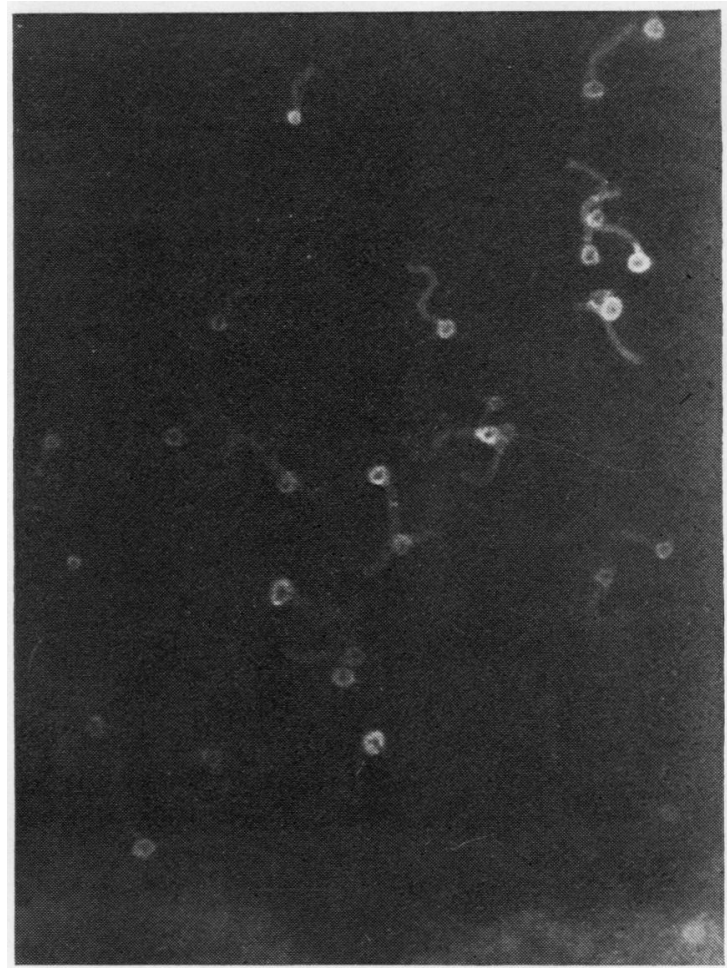

Fig 1 Immunofluorescence stuining of smear of acetone fixed germinating cells of C. albicans (group A) showing uniform staining at low serum dilution of both normal subjects and patients with candidiasis. 


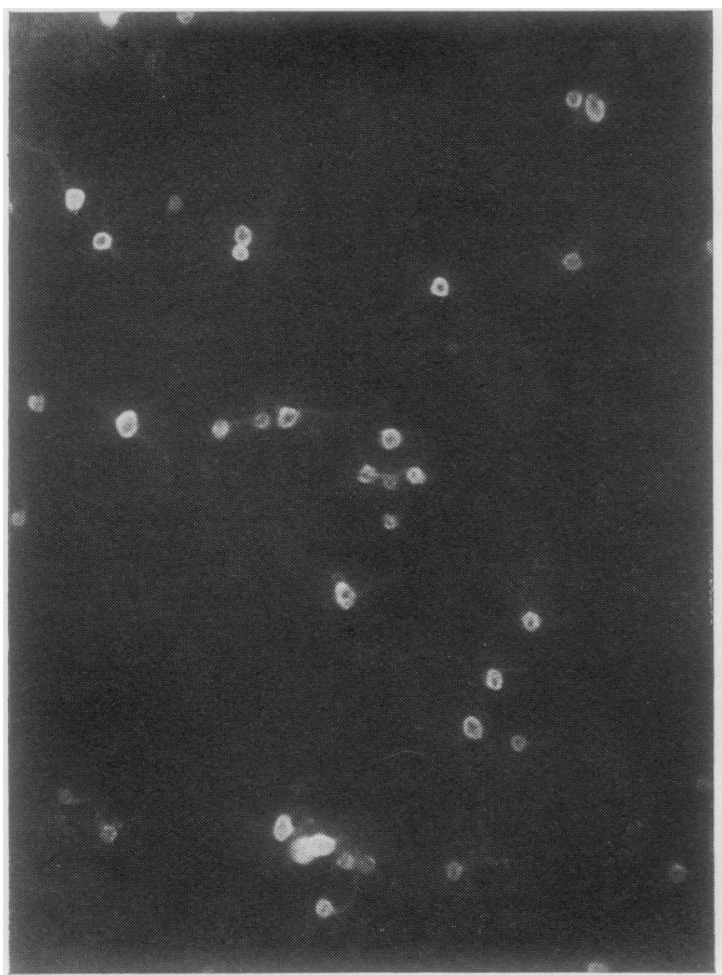

Fig 2a

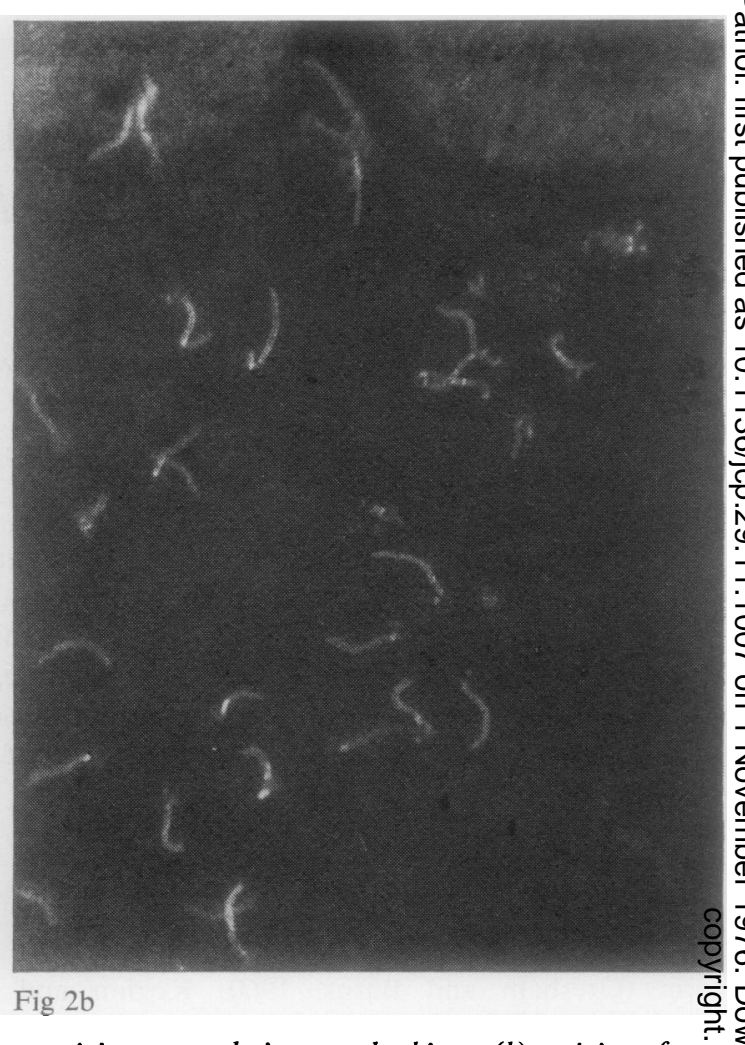

Fig 2 At high serum dilution: (a) partial immunofluorescence staining seen only in normal subjects, (b) staining of the germ tube only - as seen only in patients with candidiasis.

$\mu \mathrm{g} / \mathrm{ml})$ and sodium thioglycollate $(20 \mu \mathrm{g} / \mathrm{ml})$ was used to promote germination (Cassone et al, 1973). After inoculation the cultures were shaken continuously at $37^{\circ} \mathrm{C}$ for $2-3$ hours. Germinating organism was then harvested, washed three times with saline, and stored at $4^{\circ} \mathrm{C}$ until used.

\section{SEROLOGICAL METHODS \\ Agglutination}

Blastospore suspension in saline was prepared containing $3 \times 10^{6}$ organisms per $\mathrm{ml}$. The agglutinin titre of the serum was determined by mixing $0.5 \mathrm{ml}$ of serially diluted serum with an equal volume of the prepared blastospore suspension. The mixtures were incubated at $37^{\circ} \mathrm{C}$ for 2 hours and allowed to stand overnight at $4^{\circ} \mathrm{C}$. The agglutinin titre is the reciprocal of the maximum serum dilution giving a positive agglutination.

\section{Indirect immunofluorescence}

Anti-blastospore reactivity was determined by indirect immunofluorescence (IF-B). Smears of blastospores were prepared by adding a drop of yeast cell suspension onto glass slides, which were allowed to air-dry and then fixed in acetone for $10 \stackrel{2}{\overrightarrow{7}}$ minutes. The smears were reacted successively for 1 응 hour each with aliquots of a serially diluted serum and a 1/16 diluted fluorescence conjugate goat antiimmunoglobulin (Hyland, USA) at $37^{\circ} \mathrm{C}$ in a moist chamber. The IF-B titre of a serum is expressed as ? the reciprocal of the maximum serum dilution which gave positive immunofluorescence.

Anti-germ tube reactivity (IF-T) was determined by the indirect immunofluorescence technique, as described above, except that acetone fixed smears of 음 germinating yeast cells were used, and a positive $\rightarrow$ reaction was scored by immunofluorescence staining of the germ tubes. The titre is expressed as the $N$ reciprocal of the maximum serum dilution that gave positive immunofluorescence staining of the germ tubes.

Results

In a preliminary study we have evaluated the anti- $\stackrel{\oplus}{+}$ Candida albicans (group A) seroreactivity using 0 acetone fixed smears of the germinating cells. At a low serum dilution, uniform staining of the organism $\stackrel{\mathbb{D}}{\Omega}$ 
was observed (fig 1). But at a higher dilution of normal serum, immunofluorescence was found to be exclusively associated with the blastospores (fig $2 a$ ). Using the sera of patients with culturally confirmed candidiasis, however, the anti-blastospore reactivity was preferentially diluted out such that only residual germinating tube immunofluorescence was observed at high serum dilutions (fig 2b). This discordant seroreactivity therefore suggests that the antigenic contents of the blastospore and the germinating tube are distinctive.

The above results also reflect a qualitatively different antigenic stimulation caused by the organism as a parasite or as a commensal. To test this possibility further we have studied the anti- $C$. albicans (group A) seroreactivity of normal subjects and of patients with current $C$. albicans infection. Table I shows that the agglutinin (A) and the antiblastospores (IF-B) and anti-germinating tube (JF-T) immunofluorescence titres were significantly increased in the infected subjects. The increase in anti-T (IF-T) was, however, the most marked.

\begin{tabular}{lrrll}
\hline & \multicolumn{2}{c}{ Mean Titre } & \\
\cline { 2 - 3 } & Patients & Controls & P \\
\hline IF-T & $2582( \pm 474)$ & $113( \pm 22)$ & $<0.001$ \\
IF-B & $931( \pm 368)$ & $160( \pm 22)$ & $<0.05$ \\
A & $325( \pm 109)$ & $86( \pm 22)$ & $<0.05$ \\
\hline
\end{tabular}

Table I Anti-C. albicans seroreactivities in normal subjects and patients infected with $\mathrm{C}$. albicans

The anti-C. albicans seroreactivities, as determined by the two different serological methods, were compared by analysing the linear regression of the immunofluorescence titres on the agglutinin titres (A). The IF-B titres of both normal and patients' sera were thus found to correlate with the corresponding agglutinin titres (coefficient of correlation = 0.700) (fig 3). The IF-T titres of the patients and the normal subjects were found to regress differently on the corresponding agglutinin titres (A) although the slopes of the two linear regression lines were similar (fig 4).

\section{Discussion}

Infections with commensal organisms have become increasingly prevalent in recent years. Because of their ubiquitous presence, it is often difficult to ascertain the exact significance of laboratory findings such as positive isolations of these organisms from clinical specimens or an increase in serum antibodies against these organisms. Although an increase in agglutinin or IF-B titres has been observed during $C$. albicans infection, the persistent level of the same

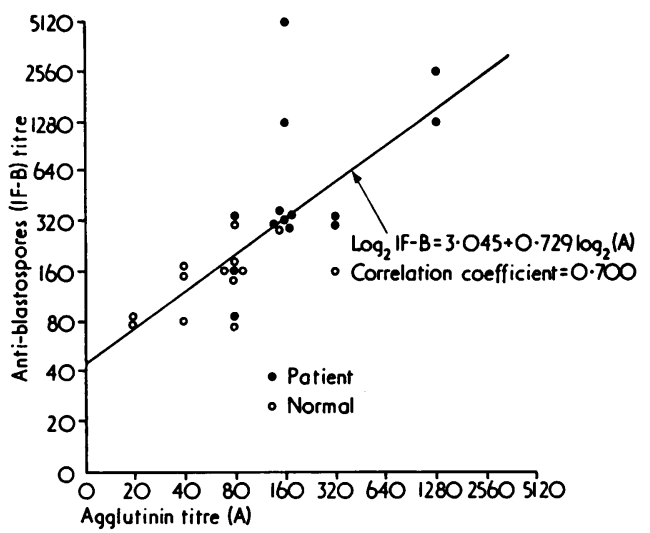

Fig 3 Linear regression of anti-blastospore immunofluorescence titres (IF-B) on agglutinin titres of sera of normal subjects $(O)$ and patients $(\circlearrowleft)$.

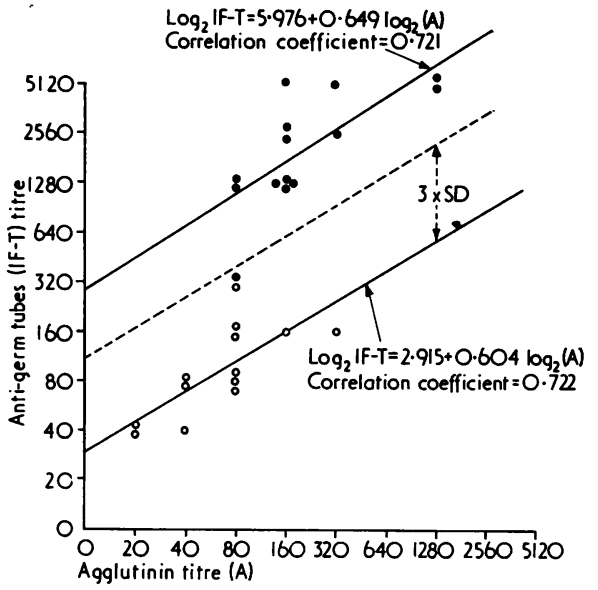

Fig 4 Linear regression of anti-germ tube immunofluorescence titre (IF-T) on agglutinin titre of sera of normal subjects $(\bigcirc)$ and patients $(\bullet)$.

seroreactivity observed among the normal subjects renders it difficult to discriminate infected individuals. The anti-germ tube immunofluorescent assay, in contrast, appeared to provide a more acute reflection of the infected state since the increase in IF-T titre in $C$. albicans infection was more pronounced than the corresponding increases in the IF-B or agglutinin titres. This is consistent with the histological findings that the mycelial growth phase invariably occurs during infection with $C$. albicans (Winner, 1969).

On the basis of the present data it is apparent that the immunofluorescent and agglutinin assays are 
related in their specificities, the immunofluorescent assays being the more sensitive. The results of this analysis also indicate that the IF-T titres are the more acute reflection of $C$. albicans infection, and an IF-T titre of 640 may be regarded as presumptive evidence of infection. Allowing an assay error of $\pm \log 2$, it may be anticipated that the detection rate of $C$. albicans infection will occur maximally at $\frac{14}{14}$ and minimally at $\frac{13}{14}$. The maximum and minimum rate of occurrence of 'false positives', on the other hand, may be anticipated to be $\frac{1}{13}$ and $\frac{0}{13}$ respectively. By setting presumptive IF-B and agglutinin titres at 160 and 80 respectively, it is apparent that these titres are less discriminatory for C. albicans infection (table II).

\begin{tabular}{|c|c|c|c|c|c|}
\hline \multirow[t]{2}{*}{$\begin{array}{l}\text { Serological } \\
\text { methods }\end{array}$} & \multirow[t]{2}{*}{$\begin{array}{l}\text { Presumptive } \\
\text { titre }\end{array}$} & \multicolumn{2}{|c|}{$\begin{array}{l}\text { Rate of } \\
\text { detection }\end{array}$} & \multicolumn{2}{|c|}{$\begin{array}{l}\text { Rate of false } \\
\text { positive }\end{array}$} \\
\hline & & Min & $\operatorname{Max}$ & Min & $\operatorname{Max}$ \\
\hline Agglutination & $80(40-160)$ & $\frac{11}{14}$ & $\frac{14}{14}$ & $\frac{2}{13}$ & $\frac{11}{13}$ \\
\hline IF-B & $160(80-320)$ & $\frac{12}{14}$ & $\frac{14}{14}$ & $\frac{2}{13}$ & $\frac{13}{13}$ \\
\hline IF-T & $640(320-1280)$ & $\frac{13}{14}$ & $\frac{14}{14}$ & $\frac{0}{13}$ & $\frac{1}{13}$ \\
\hline
\end{tabular}

Table II Anticipated rates of detection of C. albicans infection by different serological methods

The different linear regression patterns of IF-T titres on agglutinin titres observed in the normal and

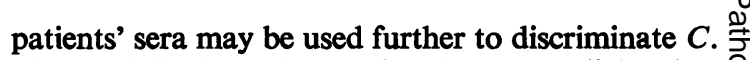
albicans infection. Thus, a line drawn parallel to but 은 at +3 standard deviations from the linear regression $\overrightarrow{\vec{F}}$ line obtained with the normal subjects has delineated all but one of the patients. Both criteria, based on absolute IF-T level and discordant seroreactivities, are now being applied in the routine serological detection of $C$. albicans infection.

\section{References}

Cassone, A., Simonetti, N., and Strippoli, V. (1973). Ultra- $\overrightarrow{\vec{\omega}}$ structural changes in the wall during germ-tube formation from blastospores of Candida albicans. J. gen. Microbiol., 77, 417-426.

Evans, E. G. V., Richardson, M. D., Odds, F. C., and N Holland, K. T. (1973). Relevance of antigenicity of Candida albicans growth phases to diagnosis of systemic $\overrightarrow{-}$ candidiasis. Brit. med. J., 4, 86-87.

Gresham, G. A. and Burns, M. (1960). Tissue invasion by $\vec{\circ}$ Candida. In Progress in the Biological Sciences in Relation to Dermatology, edited by A. Rook, pp. 174-183. Cam-음 bridge University Press, London.

Hasenclever, H. F. and Mitchell, W. O. (1960). Antigenic $Z$ relationships of Torulopsis glabrata and seven species of the genus Candida. J. Bact., 79, 677-681.

Hasenclever, H. F. and Mitchell, W. O. (1961). Antigenic $\frac{D}{3}$ studies of Candida. I. Observation of two antigenic groups in Candida albicans. J. Bact., 82, 570-573.

Kozinn, P. J. and Taschdjian, C. L. (1962). Enteric $\overrightarrow{0}$ candidiasis: diagnosis and clinical considerations. PeA atrics, 30, 71-85.

Winner, H. I. (1969). The transition from commensalism商 parasitism. Brit. J. Derm., 81, Suppl. 1, 62-68. 